\title{
Research on the value of Modern Network Technology in Music Education
}

\author{
ZHAO Hui \\ Hubei Preschool Teachers College, Wuhan, 436032, China \\ email: 459623843@qq.com
}

Key words: modern network technology; music education; communication and integration, value

\begin{abstract}
When we discuss music education, it is necessary for us to introduce modern network technique, which promotes the effect of the music. In this paper, we analyze the current situations of the network technology in the music education, and explore the values of the application of the network technology in the music education, which is designed to improve the effectiveness of the music education. Finally, it can be concluded that the network technology can enhance music education, which can offers shared resources for people, and it also leads to great changes of interaction in music education. With the assistance of the modern technique, the gap between our traditional music and foreign music is narrowed, which is able to be advanced in the quality of music education through the communication between students and media, and between students and teachers, and among students.
\end{abstract}

\section{Introduction}

Multimedia information technology plays an important role in the modernization of education, and has a significant impact on education reform as well.[1] It is an important strategy of using computer multimedia technology and network technology education to promote teaching contents and teaching methods. Under the guidance of the policy "information to promote the modernization of education, to achieve basic education by leaps and bounds," by the National Ministry of Education, the schools create a new music teaching model by integrating the information technology and music disciplines. [2] This new music teaching model changes the way of students' learning and teachers' teaching methods, in order to make student positive, active, lively, learn actively. [3] At the same time, this new approach promotes the reform on curriculum materials positively. This paper analyzes the application of multimedia network technology on music teaching reform and its influence.

\section{Current situation and problems of music education}

With the help of integrated multimedia device in the music education, music education experiences a dramatic reform, and it becomes high-tech different from the "mouth sound teaching" primitive artisanal way. [4] It is a fundamental change compare with the traditional music education. However, People, on the status quo, "a piano a book" or "a song sheet a tape recorder," seem to have become accustomed due to the impact of equipment, technology and the concept of teachers and other factors. On the one hand, we recognize the importance of information technology, teachers adopt multimedia technology and computer assisted instruction to improve the efficiency of classroom teaching. [5] On the other hand, we felt that "the IT mysticism" is subject to the impact on the concept and the actual operation of courseware design, production and complexity of the application. The problem is that music teachers like to use modern network technology to design their courses, but sometimes they are afraid of using high-tech resource because technical staff do not understand the special nature of music and music education teachers' intent, which result in both of them find it difficult to communicate.

According to the current situation, music teachers change their ideas in practice and try to do curriculum integration, in order to enhance their overall quality and ability. [6] Through continuous 
self-charging, not only can they transcribe music or songs through the computer, as well as to gather relevant information for classroom teaching by searching images and other data on the network, but also teach themselves some professional MD production, sound recording and other software. For example, they adopt COOLEDIT method for processing media information to change the tone of the recorded sound, speed, the music changes tempo, dynamics, timbre and tone. Thus, according to the requirements of different teaching contents and teaching subjects, music teachers should do the integration among the corresponding media material, design and production of small practical computer multimedia courseware for music teaching.

\section{The influence on the teaching process}

The students mainly carry out the teaching under the guidance of the teachers, and achieve the practice activities of the harmonious development, the formation of their personalities, and the transformation of their subjective world through their own cognitive activities. In the teaching process, both the students and the teaching are the important factors. The music teaching uses the network music to carry out the teaching, and treats the network teaching as the main body of the teaching or the subject of the study. The existing music teaching materials still pay attention to the system of the profession and the perfection of the knowledge points, but the combination of it with other subjects of humanities is not enough. [7] The combination of the teaching of the music skills with the musical cultural teaching of multiple disciplines is not close, if there is not the open knowledge environment. In addition, due to the pressure of the exam oriented education, the music teaching can only be confined to the classroom teaching, with the teachers, the classrooms, and the books in the center, and the time and the space cannot be fully expanded. The music teaching in the network environment is open, and the student's learning process should have some activities to implement interaction. Meanwhile, the students should have their initiatives and individuality in the selection of the learning contents, which requires that the teaching environment of the network teaching should be open. We should create information teaching environment, which is suitable for the network teaching. However, the teachers from different disciplines have different requirements for the construction of the hardware environment and the software environment. They have different requirements, which cannot be fully met in the development of the network technology.

\section{The inevitable trend of Music Teaching Reform with the help of the multimedia network technology}

With the assistance of modern network technology, Music teaching can be fully displayed in the areas of aesthetic music art, joviality and other characteristics.

\section{A. with the application of multimedia to create conducive situations and more vivid image}

Music is the art of listening, but also some kind of outpouring of emotion. In concert or the process of appreciating music, the most important thing is to understand the music; otherwise you may fail to achieve musical aesthetic purposes. With the help of multimedia, you are able to display music in the form of the intuitive situation, so that students can appreciate music image at the first sight. When teachers teach how to sing the songs "Red Star Song", they always allow students to see the film "Sparkling Red Star" in the episode "Red Star Song". Meanwhile, students may get a better understanding of the story "Red star song" at the first time they appreciate it, because the image of the music show vivid impression in the student's mind, which provide material to music creation image. Generally speaking, students are difficult to understand music image, only when the media provides music image specifically. For example, when they play piano music "Defend the Yellow River", they use multimedia to create the Yellow stormy scene unfolded, in order to make music emotionally. It would be easier for students having better performance after they fully understand the music.

\section{B. In favor of pluralism and cultural infiltration by using multimedia}


Music's diversity exists not only in its form of expression, singing method, creative approach, but it also has its own rich cultural background. Take Chinese folk song for instance; various ethnic groups have so many different customs, architectures, language, clothing, dance that many cultures have infiltrated in their music. In the classroom teaching, it far from satisfaction for teachers only using the language, pictures in their instruction. What teachers suggest to do is to use multimedia information to enable students getting better understanding about the courses. This music teaching method provides a good chance for students understanding the inner meaning of the music better, and comprehending relevant nations' cultures. When I make the preparation of teaching the song "how happy are Dong Jia children," I search the information of the Dong ethnic architecture, dance forms, customs, and clothing and then put all these into my courseware to help students fully understand the culture of this nation, thus naturally understand the content and inner meaning when they perform it.

\section{C. enhancing students' interest by using the multimedia network technology}

Due to the special nature of multimedia, teachers can put the design of the whole class into the computer. In the teaching process, teachers can make the writing on the blackboard clearer in a holistic and systemic way. They can make the music richer knowledge interesting by combining multi-level and multi-order thinking. By using modern network media, the students recorded song and upload to the internet, thus broadening their horizons, which let them experience the joy of success, stimulate their interest in music and creative passion. What' more, this approach provide a guidance for students to watch some highly motivated music program, such as "I'm a singer," "Chinese song", so that students plug in a dream wings, fly freely in the ocean of music. Music teaching with multimedia is the inevitable trend in modern education, which will make multimedia classroom teaching become more interesting.

\section{Proper use of network technology based on advanced educational philosophy}

With the development of quality education in conventional teaching, multimedia teaching with the sound, light, electricity, and modern high-tech is one of the new means of teaching, which transforms classroom teaching into a new type of teaching state. The methodology of teaching is determined by the teachers and student rather than by information technology, because the interaction between teachers and students is to constitute the classroom. Classroom teaching is made up of teachers and students have activities can not rely on technology, but should be based on advanced educational philosophy as a guide. Information technology and curriculum integration is the nature and content of the requirements under the guiding theory of education. As the core of information technology, the computer network promotes independent learning as cognitive tools and emotional motivation tools, in order to richening learning environment. Music class is to develop students' musical abilities, no matter what the teacher teaching methods, should be valued in the music education.

\section{The values of the network technology in the music education}

The emergence of the music with network technology not only enriches the music cultures, but also promotes the development of the music education. The music with network technology is the inheritance and innovation of the traditional music and it is a product of the development of technology, which has a very high educational value. [8] With the development of the music education in the new era, the network technology has gradually been introduced into the field of the music education, and has been integrated with the music education. This fusion makes the music education can keep a lot of the new characteristics while maintain the traditions at the same time, giving the music education the characteristics. It makes the teaching ideas of the music educators from the closed and single to the open and pluralistic, so that the teachers' subjectivity and leading roles have undergone the changes and the teaching methods and ways are flexible and diversified. The teaching contents can break through the limits of the books, and so on. At the same time, the application of the music with network technology in the field of the education has also raised the 
higher requirements for the quality of the teachers. It requires that the teachers should improve the abilities to use the network and the media tools, and master the ways of using the network and the media tools, based on which we should carry on the comprehensive literacy of the analysis, teaching, and evaluation of the network music, to improve the overall understanding of the music education and the specific operational abilities.

\section{Conclusion}

The prosperity and development of the network music completely breaks the previous music learning paradigm and the single way, and expands the music learning channels, which shows a variety of the learning ways. Similarly, it can be displayed in front of the teachers and the students through the teaching media in different forms, as the objects of the common learning of the teachers and the students and the media of the indirect education of the teachers. Through the videos, audios and other different types of the online music, the teachers can carry out the direct teaching of the students, and guide the students to carry out a series of the learning activities, such as the imitation, analysis, and practice and so on, so as to make music classroom teaching become more vivid and lively. The application of the network music enriches the teaching models and the learning ways of music, which is also the concrete manifestation of the values of the network music in the music education.

\section{Reference}

[1] Chen Fei, Lu Li. Study on the values of the network music in the music education in middle schools [J], Research in Teaching, 2014, (01)

[2] Hewen Hailiang. Peng Haoyu preparing: Sing to the heart and soul: Phmphlet for Practical Network sing” [M]. Chang Sha: Hunan Literature and Arts Press, 2005.

[3] Wang Yin. Analysis of the values of the network music in the high school music education [J], High School Years, 2014, (14)

[4] Zheng Suijin. “Chinese Public Music”, [M]. Beijing: College of Beijing Radio Press.2005.

[5] Zhou Danni. Analysis of the values of the network music in the music education in middle schools [J], Yellow River of the Song, 2014, (15)

[6] Xu Xingming, Du Hua, Zhang Jing. “The Art of Network”, [M].Beijing: College of Beijing Radio Press, 2002, 1.

[7] Gao Lei. On the influence of the network songs on the middle school music education [J], Not-only Music, 2012, (06)

[8] Ji Lijun. Study of the inquiry learning of music under the network environment [J], New Curriculum Learning, 2011, (12) 